\title{
The Effects of Morphological Structure and Fatigue on the Passing Skill in Pre-Pubescent Basketball Players
}

\author{
Umut Canl $1^{1}$, Yasemin $\mathrm{Ar}^{1}{ }^{1} \&$ İlker Özmutlu ${ }^{1}$ \\ ${ }^{1}$ School of Physical Education and Sports, Tekirdag Namik Kemal University, Tekirdag, Turkey \\ Correspondence: Umut Canlı, School of Physical Education and Sports, Tekirdag Namik Kemal University, Tekirdag, \\ 59000, Turkey.
}

Received: December 4, 2018

Accepted: December 5, 2018 Online Published: December 29, 2018

doi:10.11114/jets.v6i12a.3921

URL: https://doi.org/10.11114/jets.v6i12a.3921

\begin{abstract}
The aim of the study was to examine the effects of morphological structures and fatigue levels of pre-pubescent basketball players on basketball passing skill. Twenty-three male basketball players (age $=10.5 \pm 0.71$ ) who train regularly participated in the study voluntarily. The American Alliance for Health, Physical Education, Recreation and Dance (AAHPERD) Basketball Pass Test was used to determine participants' passing skills. To determine the fatigue intensity participants were required to perform as many squat thrusts as possible in one minute. The Heath-Carter method was used to determine somatotype characteristics. In the statistical analysis, Spearman Rank Correlation Coefficient was used in determining the level of relationship between parameters, while Wilcoxon Signed Rank Test was used to determine the difference between rest passing skill and fatigue passing skill. The endomorphic structure had a negative correlation with rest passing and fatigue passing scores $($ rho $=-0.42,-0.55 ; \mathrm{p}<0.05, \mathrm{p}<0.01$, respectively). The mesomorphic structure had a negative correlation with fatigue passing score (rho $=-0.45 ; \mathrm{p}<0.05)$. A moderate positive correlation was found with the fatigue passing score of the ectomorpic structure (rho $=0.58, \mathrm{p}<0.01$ ). Significant differences were found between the passing scores of basketball players' rest and fatigue $(\mathrm{p}<0.01)$. As a result, it was determined that both rest and fatigue passing scores decreased with the increased of the endomorphic structure representing the fatness feature and also fatigue passing scores decreased with the increased of the mesomorphic structure. But, fatigue passing score increased with the increased of the ectomorphic structures of basketball players. In addition, the results of the study showed that as the fatigue levels of pre-pubescent basketball players increased, the passing skill levels decreased.
\end{abstract}

Keywords: basketball, passing, somototype structure, fatigue

\section{Introduction}

Body shape and functions are leading factors in order to gain higher-up sportive performance (Fox, Bowers and Foss, 2012). The ideal composition and somatotype of the body is an important function of any branch of sports. Anthropometric measurements and somatotype have become significant in determining whether an athlete is appropriate for a certain branch of sports or not from the first studies to the present (Hopper, 1997). Somatotype, which means identifying the morphological structure of the body, classifies the human body into three basic components as endomorphy, mesomorphy and ectomorphy (Carter and Heath, 1990; Özer, 1993). In the studies carried on the sportsmen, it has been presented that body composition and somatotype features differ in different populations and branches of sports. For this reason, many researchers have studied on different populations branches of sports, developed body composition ratios aimed at this branch of sport and taken advantage of these ratios in their studies (Carter and Heath, 1990; Heyward and Stolarczyk, 1996). The athlete's having basic motoric features is possible by the fact that his/her morphological and physiological features are appropriate for this branch of sport (Kilic, Gunay and Gokdemir, 2000). Important developments in all branches of sports are the production of the evaluation of basic and specific anthropometric and kinesiological characters of the athletes (Heimer, Misigoj and Medved, 1988). Fatigue may also be an important factor between winning and losing especially in sport environment and a team sport like basketball as well as morphological structure (Lyons, Al-Nakeeb and Nevill, 2006). Fatigue is a complicated concept including both psychological and a range of physiological factors (Astrand, Rodahl, Dahl and Stromme, 2003). In addition, fatigue should not be considered as a single process. It is a rather complicated incident which plays role in more than one place in both central nervous system and muscles and consisting of numerous different components (McKenna, 
2003). When we have examined the studies aimed at the effects of fatigue on some skills and performances of the basketball players, Ahmed (2013) has stated in his study on young basketball players that fatigue decreases the passing hit rate. Ivoilov, Smirnov, Carlson and Garkavenko (1981) have stated in their study that shooting performance in basketball significantly gets worse with the effect of fatigue. Legros, Delignieres, Durand and Brisswalter (1992) have stated that the fatigue level of higher-up basketball players after $95 \%$ and $125 \% \mathrm{VO}_{2}$ maximum level of loading causes fail in simple reactions and there is an increase in failure rates even though they perform better in chosen reaction times.

Basketball is a game which includes explosive actions such as speed, acceleration, rebound, shoot, lay-up, block, fast break and whose pace consistently changes. Moreover, it includes dynamic, explosive skills that need to be repeated over and over again (Gore, 2000). The some studies show that fatigue can affect negatively the player's skill and coordination performance in any part of the game (Ivoilov et al., 1981; Forestier and Nougier, 1998; Kellis, Katis and Vrabas, 2006; Legros et al., 1992; Lyons et al., 2006). Although there are studies aimed at the effect of fatigue on skills of elite and non-elite adult and young basketball players, there are not any that kind of study for pre-pubescent basketball players. In addition, while knowing the effect of morphological structure on performances special to the branches of sports is effective for trainers in seeking and selecting sportsmen, knowing also how much the technique is affected at which fatigue level is quite important in branch of basketball in view of trainers and educators (Mülazimoğlu, 2012). From this point of view, determining the impact of morphological structure and fatigue on the passing skill in pre-pubescent basketball players composes the aim of the study.

\section{Method}

\subsection{Participants}

Twenty-three male basketball players who train regularly and compete in youth basketball league participated voluntarily in the study. All testing and measurements procedures were fully explained, and participants (or their parents in underage players) signed written informed consent before begin of the study. The study was conducted according to the declaration of Helsinki.

\subsection{Measurements and Tests}

\subsubsection{Body Height and Body Weight Measurements}

Stadiometer with $0.1 \mathrm{~cm}$ degree of accuracy was used for body height measurements. Body height was measured with the participants' feet are unclothed, their body weight is distributed equally on both feet, heels are jointed and touching the stadiometer, head is on the Frankfort plane, arms swinging from shoulders freely to the sides. Body weights of the participants were measured by electronical bascule with $0.1 \mathrm{~kg}$ degree of accuracy with the participants' feet are unclothed and they only have shorts and T-shirt. The data obtained was recorded in kg (Özer, 2009).

\subsubsection{Circumference Measurements}

Anatomic parts were determined studiously before circumference measurements. Circumference measurements values was measured with straight angles to the long axis of the body or its parts. Measurements was carried out by using Gulick Measurement Tape and it has been carefully observed that the skin should not be tighten and pitted (Tamer, 2000). Measurements was carried out twice for each participant and their average was determined. On the condition that the difference between these two measurements is more than $7 \mathrm{~mm}$, the test was repeated (Koz, M.). Circumferences of calves and biceps in flexion of the participants were measured.

\subsubsection{Diameter Measurements}

Holtain brand calibrated sliding caliper was used for diameter measurements. Before the measurement, the points to be measured were determined by fingers. The tip of the sliding caliper was pressured on the soft tissue as much as possible. In this way, the results of the measurements were ensured to be more reliable (Tamer, 2000). Each measurement was carried out twice. The participants' diameters of humerus and femur epicondyle were measured.

\subsubsection{Skinfold Measurement}

In skinfold measurement, Holtain skinfold caliper that pressures $10 \mathrm{~g} / \mathrm{sq}$ in each angle was used. Skinfold measurement values was measuremented from the right side of the body. Folding was done with the thumb and forefinger in the way that there is no muscular tissue behind the folded skin. The caliper was located $1 \mathrm{~cm}$ far from the area folded by the fingers and the measurements were recorded within 2-4 seconds without relaxing the fingers holding the skin. Each measurement was repeated twice (Ghorbanzadeh, Akalan, Sahin and Kirazc1, 2011). Skinfold measurement of the participants' triceps, subscapula, suprailiac and medial calf was carried out.

\subsubsection{Somatotype Assessment}

The somatotype values of the experimental subjects were determined by Health Carter somatotype method. According 
to this method, somatotype values were specified by the participants' measurements of body height, body weight, and circumference of calf and biceps in flexion, diameters of humerus and femur and skinfold measurement of triceps, subscapula, suprailiac and medial calf (Ross and Marfell-Jones, 1991).

\subsubsection{Determining the Level of Fatigue}

The players' high fatigue levels were specified by calculating 90 percent of the total score of the squad pushing movement carried out in one minute. Each player was provided to form the fatigue intension according to their level of physical fitness. It was paid attention to implement the movement at the same pace. As the squad pushing movement is effective on the muscle groups used in passing test, this test was used (Lyons et., 2006).

\subsubsection{Basketball Passing Test}

This test was chosen as it is suitable for assessing the skill of passing. The test was certified by Association of American Health, Physical Education, Recreation and Dance (AAHPERD) in 1984. The reliability coefficients of the test-retest are between 0.84 and 0.97 , so the test is both valid and reliable.

In the test, the players were supposed to pass each other fast and well-directed which are two main elements in basketball (Krause, Meyer and Meyer, 1999). A smooth 30 feet wall surface is necessary for the implementation of the test. A 26 feet long bordering line was marked parallel to the test wall and 8 feet far. 6 square boxes 2 feet each were determined on the test wall as 2 feet far from each other. Starting from the left side of the test wall, A, C and E target boxes were drawn 5 feet high from the ground; B, D and F target boxes were drawn 3 feet high from the ground.

The player holds the ball behind the bordering line at the left target area and faces the wall (A). Assistant trainer plays the $\mathrm{CD}$ which counts backwards with three beep sound and starts the test with the fourth beep sound. Following the fourth beep sound, each player passes the ball with chest pass (A) to the first target (A), takes the ball coming from the wall again and passes the ball with chest pass again (B) to the second target (B). The player continues this movement until the player reaches the last target $(\mathrm{F})$. At the last target area $(\mathrm{F})$, after performing the chest pass twice, the player comes back to the starting point by passing the ball with chest pass at $\mathrm{E}, \mathrm{D}$ and $\mathrm{C}$ target areas in turn. The implementation time of the test is 30 seconds. Only chest pass is allowed in the test. The scoring is as follows:

- Two points are scored for each chest pass touching the target or the target lines.

- One point is scored for each chest pass touching the area between the targets.

- No point is scored on the condition that the player's foot touches the starting line or the chest pass touches the areas other than the target areas.

Test score was obtained by totaling the scores of success passing in 30 seconds.

\subsection{Procedures}

After explaining the pass test protocol and the protocol related with the squad pushing movement used in determining the levels of fatigue to each participant, they were provided an opportunity to make a trial in order to know the tests. Before determining the levels of fatigue, 10 minutes time was given to the participants for individual warm-up and stretching exercises. The participants were motivated during the implementation of the movement in order to perform the squad pushing movement in maximum effort and as much as possible in one minute. High intension level was determined by calculating $90 \%$ of maximum number of squad pushing movement performed in one minute.

In order to minimize the effect of the previous tests, 24 hours of resting period was given between successive test sessions. 10 minutes time was given to the participants for individual warm-up and stretching exercises next day within the same time period. The participants were required to complete the movement when they reached the number of high intensity levels determined by the "start" instruction and perform the pass skill test by coming in front of the line. Passing skills scores of the participants both at rest and fatigue were specified and the effect of fatigue on passing skill was tried to be determined.

\subsection{Statistical Analyses}

All statistical analyses were performed using the SPSS version 21.0 software (Statistical Package for Social Sciences; SPSS Inc., Chicago, IL, USA). The minimum, maximum values, arithmetic means, and standard deviations of all data were calculated. Spearman Rank Correlation Coefficient was used in determining the level of relationship between parameters. Wilcoxon Signed Rank Test was used to determine the difference between rest passing skill and fatigue passing skill. The level of significance was set at $\mathrm{p}<0.05$. 


\section{Results}

Table 1. Data of the participants' descriptive values

\begin{tabular}{lccccc}
\hline & $\mathrm{n}$ & Minimum & Maximum & Mean & $\mathrm{Sd}$ \\
\hline Age (year) & 23 & 8.8 & 11.2 & 10.5 & 0.71 \\
\hline Training experience (year) & 23 & 1.0 & 5.0 & 2.6 & 1.36 \\
\hline Body height $(\mathrm{cm})$ & 23 & 134.9 & 157.9 & 147.1 & 6.91 \\
\hline Body weight $(\mathrm{kg})$ & 23 & 28.0 & 59.0 & 41.0 & 9.00 \\
\hline Endomorphy & 23 & 1.6 & 5.2 & 3.3 & 1.18 \\
\hline Mesomorphy & 23 & 1.9 & 5.8 & 4.2 & 1.02 \\
\hline Ectomorphy & 23 & 1.0 & 5.0 & 2.8 & 1.21
\end{tabular}

The mean age of the participants is $10.5 \pm 0.71$ years; training experience mean is $2.6 \pm 1.36$ years. The mean body height of the participants is $147.1 \pm 6.91 \mathrm{~cm}$. Their mean body weight is $41.0 \pm 9.00 \mathrm{~kg}$. Endomorphy mean of the participants is $3.3 \pm 1.18$, Mesomorphy average is $4.2 \pm 1.02$, and Ectomorphy average is $2.8 \pm 1.21$.

Table 2. The relationship between the participants' somatotype structures and rest passing skill scores and fatigue passing skill scores

\begin{tabular}{llll}
\hline Variables & Endomorph structure & Mesomorph structure & Ectomorph structure \\
\hline Rest passing & $-0.43^{*}$ & -0.26 & 0.38 \\
\hline Fatigue passing & $-0.56^{* *}$ & $-0.46^{*}$ & $0.58^{* *}$ \\
\hline
\end{tabular}

$\mathbf{p}<0.05^{*}, \mathbf{p}<0.01 * *$

A moderate level negative relationship of the endomorphic structures of the participants with rest and fatigue passing skill scores was determined (respectively, rho $=-0.43 ; \mathrm{p}<0.05$. rho $=-0.56 ; \mathrm{p}<0.01$ ). Mesomorphic structures of the participants were found a moderate negative relationship with fatigue passing skill scores. (rho $=-46 ; \mathrm{p}<0.05 \mathrm{~A}$ moderate positive relationship was found between the fatigue passing skill scores of the ectomorphic structures of the participants (rho $=0.58 ; \mathrm{p}<0.01$ ).

Table 3. The comparison of rest and fatigue passing skill scores of participants

\begin{tabular}{|c|c|c|c|c|c|}
\hline Pre-test-Post-test & $\mathrm{n}$ & Mean Rank & Total Rank & $\mathrm{Z}$ & $\mathrm{p}$ \\
\hline Negative rank & 15 & 9.6 & 144.0 & \multirow{4}{*}{-3.243} & \multirow{4}{*}{0.00} \\
\hline Positive rank & 2 & 4.5 & 9.0 & & \\
\hline Equal & 6 & & & & \\
\hline Total & 23 & & & & \\
\hline
\end{tabular}

A significant difference was found between the rest passing skill scores of the participants and fatigue passing skill scores $(z=-3.243 ; p<0.05)$. Considering rank totals of the difference scores, it was determined that this difference was in countenance with the negative ranks difference.

\section{Discussion}

The study had two aims. The first one was to determine the relationship between the morphological structures of pre-pubescent basketball players and their passing skills. The second one was to execute whether fatigue had effect on passing skill.

It has been stated that anthropometry affects the performance and it has relationship with other factors affecting the performance (Cicchella et al., 2009). For this reason, determining the morphological and physiological structures is quite important (Carter and Heath, 1990; Heyward and Stolarczyk, 1996 Ross and Marfell-Jones 1991; Zorba and Ziyagil, 1995). A moderate level negative relationship was specified between the endomorph features of the basketball players and both rest and fatigue passing skill scores. While mesomorph structures of the participants was moderate level negative relationship with the fatigue passing skill scores, ectomorph structures of the participants was moderate level positive relationship with the fatigue passing skill scores. It can be said that when endomorphy which represents the highness of the fattiness rate of the body (Carter and Heath, 1990; Özer, 1993) increases among pre-pubescent basketball players, it causes decrease in passing skill scores they perform when they are both at rest and tired. It can be 
stated that when mesomorphy which represents the development and strength of skeletal muscle structure (Carter and Heath, 1990; Özer, 1993) it causes decrease in passing skill scores they perform when they are tired. It can be stated that when ectomorphy which is related with the weakness of skeletal muscle structure (Carter and Heath, 1990; Özer, 1993) it causes increase in passing skill scores they perform when they are tired. Voisard (1954) has stated when he has examined the relationship between somatotype and performance among boys aged 10-13 that endomorphy affects performance negatively, ectomorphy affects positively and mesomorph component has no relationship with performance. Ayan and Erol (2006) has specified in their study which they have assessed the relationship between somatotype features of the Turkish Young National basketball team and their performances that there is a low-level negative relationship between endomorphy value and vertical jump and stopping long jump, low-level positive relationship between mesomorphy value and vertical jump and stopping long jump, low-level negative relationship with 20 meters speed. Low-level positive relationship between ectomorphy value and vertical jump and 20 meters speed. While Raudsepp and Jurimae (1996) has claimed that the relationship between physical fitness and somatotype has no importance, Clarke (1971) has determined in his study on boys aged 9-12 that there are weak and moderate level relationships between endomorphy and mesomorphy and strength, weak and moderate level negative relationships between ectomorphy and strength. Canlı (2017) has stated in his study that while there are negative relationships between endomorph and mesomorph structures of the adolescent basketball players and their basketball skills, there are positive relationships with ectomorph features. The results of this study resemble the results of our study.

One of the hypotheses we try to designate in our study is whether fatigue has effect on passing skill or not. In this context, there has been a significant difference when passing skill scores performed when they are at rest and tired have been compared. This difference results from the fact that passing skill scores performed when the players are tired are lower than the passing skill scores performed when the players are at rest. Lyons et al. (2006) have stated in their study on examining the level of impact of fatigue on passing technique at elite and non-elite basketball players that there is a significant difference between the passing scores performed when they are at rest and the scores performed when they are tired. This impact is higher for the non-elite basketball players. They have stated that there is a significant difference between passing scores performed when elite and non-elite group are at rest and moderate fatigue level passing scores (70\%) and high-tiredness passing scores (90\%). They have presented a high significance of difference in passing scores according to the fatigue levels of both groups (at rest, 70\% and 90\%) (Lyons et al., 2006). This study resembles the results of our study. McMorris, Gibbs, Palmer, Payne and Torpey (1994) have stated that passing performance at moderate level fatigue is better than passing performance performed when the players are at rest. Uygur, Goktepe, Ak, Karabörk and Korkusuz (2010) have executed that higher-up basketball players can withstand total body fatigue during free throw performance. Mülazimoğlu (2012) has specified in his study named the impact of fatigue on shooting technique of young basketball players that when the fatigue levels of young basketball players increase, their success of shooting decreases. These studies and the results of our study have parallels with each other in view of the fact that fatigue affects passing and shooting skill which are important techniques in basketball. All these studies execute that fatigue is an important determiner over passing and other skills of basketball players.

\section{Conclusions and Recommendations}

- As the endomorphic scores of the pre-pubescent basketball players increased, both the rest and the fatigue of the passing skill scores decreased. Therefore, it can be said that the endomorphic structure negatively affects the passing skill.

- As the mesomorphy scores increased, fatigue passing skill scores rust decreased. This showed that mesomorphy, which represents the muscular structure, had no positive effect on fatigue.

- As a result of increased ectomorphy scores, it was determined that there was an increase in fatigue passing skill scores. As a result of this finding, it was revealed that the fatigue passing skills of basketball players with ectomorphic characteristics were not negatively affected by fatigue.

- At the end of the comparison of passing skill scores performed when the players were at rest and tired, it was determined that there was a decrease in passing skill scores performed when the players were tired. As a result of this finding, it can be said that fatigue affects passing skill of pre-pubescent basketball players negatively.

- The results of this study can be a resource especially for trainers and educators working with these age groups for morphological structure criteria which is one of the factors at the stage of seeking and choosing the players who can put forward the basic skills required for the branch.

- The negative effects of fatigue on skill performance should be minimized by designing training program appropriate for the branch of sports and developmental features of the players at these ages. 


\section{References}

Ahmed, T. (2013). The effect of upper extremity fatigue on grip strenght and passing accuracy in junior basketball players. Journal of Human Kinetics, 37, 71-79. https://doi.org/10.2478/hukin-2013-0027

Astrand, P., Rodahl, K., Dahl, H. A., \& Stromme, S. B. (2003). Textbook of work physiology: Physiological bases of exercise. 4th edition. Champaign Illinois: Human Kinetics.

Ayan, V., \& Erol, A. E. (2016). The study of the somatotype structures and the performance characteristics of turkey's u15 men's national basketball team players. Kastamonu Education Journal, 24(4), 2089-2098.

Canl1, U. (2017). The Effect of somatotype profiles of adolescent basketball players on biomotoric characteristics and ability. IOSR Journal of Sports and Physical Education, 4, 61-66. https://doi.org/10.9790/6737-04016166

Carter, L. J. E., \& Heath, B. H. (1990). Somatotyping-development and aplications. New York: Cambridge University Press.

Cicchella, A., Jidong, L., Jurimae, T., Zini, M., Passariello, C., \& Rizzo, L. (2009). Antropometric comparison between young estonian ve chinese swimmers. Journal of Human Sport and Exercise, 4(2), 154-160. https://doi.org/10.4100/jhse.2009.42.08

Clarke, H. H. (1971). Physical and motor tests in the metford boys growt study. New Jersey: Prentice Hall.

Forestier, N., \& Nougier, V. (1998). The effects of muscular fatigue on the coordination of a multijoint movement in human. Neuroscience Letters, 252(3), 187-190. https://doi.org/10.1016/S0304-3940(98)00584-9

Fox, E. L., Bowers, R. W., Foss, M. L., \& Trans, M. C. (2012). The physiological basis of physical education and athletics. Ankara: Sports Publisher.

Ghorbanzadeh, B., Akalan, C., Sahin, M., \& Kirazc1, S. (2011). The evaluatıon of somatotype profile of turkısh natıonal taekwondo team. Sports Sciences, 6(3), 169-177.

Gore, C. J. (2000). Physiological tests for elite athletes. Champaign Illinois: Human Kinetics.

Heimer, S., Misigoj, M., \& Medved, V. (1988). Some anthropological of top volleyball players in SFR Yugoslavia. The Journal of Sports Medicine Fitness, 28, 200-208.

Heyward, V. H., \& Stolarczyk, L. M. (1996). Applied body composition assessment. USA: Human Kinetics.

Hopper, D. M. (1997). Somatotype in high performance female netball players may influence player position and the incidence of lower limb and back injuries. British Journal of Sports Medicine, 31(3), 97-199. https://doi.org/10.1136/bjsm.31.3.197

Ivoilov, A. V., Smirnov, Y. G., Carlson, J. S., \& Garkavenko, A. G. (1981). Effects of progressive fatigue on shooting accuracy. The Theory and Practice of Physical Training Culture, 7, 12-14.

Kellis, E., Katis, A., \& Vrabas, S. (2006). Effects of an intermittent exercise fatigue protocol on biomechanics of soccer kick performance. Scandinavian Journal of Medicine \& Science in Sports, 16, 334-344. https://doi.org/10.1111/j.1600-0838.2005.00496.x

Kilic, F., Gunay, M., \& Gokdemir, K. (2000). Examination of some physiological, biomotoric and postural structures of promising female basketball players. 1. Gazi Physical Education and Sports Congress, Ankara.

Koz, M. Body composition and its relationship with sportive performance. http://80.251.40.59/sports.ankara.edu.tr/koz/egz-fizII/vucut.kompz.egz.pdf

Krause, J. V., Meyer, D., \& Meyer, J. (1999). Basketball skills and drills. 2nd edition. Champaign Illinois: Human Kinetics.

Legros, P., Delignieres, D., Durand, M., \& Brisswalter, J. (1992). Influence of physical effort on simple and choice reaction time in high-level basketball players. Science and Sports, 7, 9-14. https://doi.org/10.1016/S0765-1597(05)80133-9

Lyons, M., Al-Nakeeb, Y., \& Nevill, A. (2006). The impact of moderate and high intensity total body fatigue on passing accuracy in expert and novice basketball players. Journal of Sports Science and Medicine, 5, 215-227.

McKenna, M. J. (2003). Mechanisms of muscle fatigue, In: M. Hargreaves, \& J. Hawley (Eds.), Physiological bases of sport performance. New South Wales: McGraw-Hill.

McMorris, T., Gibbs, C., Palmer, J., Payne, A., \& Torpey, N. (1994). Exercise and performance of a motor skill. Research Supplement, 15, 23-27. 
Mülazimoğlu, O. (2012). The impact of fatigue on shooting in young basketball players. Selçuk University Journal of Physical Education and Sport Science, 14(1), 37-41.

Özer, M. K. (1993). Anthropometry: Morphological planning in sport. İstanbul: Kazanc1 Publisher.

Özer, M. K. (2009). Morphological planning in kinantropometry sport. 2nd Edition. Ankara: Nobel Printing House.

Raudsepp, L., \& Jurimae, T. (1996). Somatotype and physical fitness of prepubertal children. Collegium Antropologicum, 20(1), 53-59.

Ross, W. D., \& Marfell-Jones, M. J. (1991). Physiological testing of the high-performance athlete, In: D. J MacDougall, A. H. Wenger, H. J. (Eds.), Kinanthropometry. Illinois: Human Kinetics.

Tamer, K. (2000). Physical and physiological performance measurement and evaluation in sport. Ankara: Bagirgan Publisher.

Uygur, M., Goktepe, A., Ak, E., Karabörk, H., \& Korkusuz, F. (2010). The effect of fatigue on the kinematics of free throw shooting in basketball. Journal of Human Kinetics, 24, 51-56. https://doi.org/10.2478/v10078-010-0019-0

Voisard, P. P. (1954). A study of the relationship between body build and motor educability of elementary school boys ages 10-13. Unpublished master thesis. The University of Illinois.

Zorba, E., \& Ziyagil, M. A. (1995). Body composition and measurement methods for physical education and sports scientists. Ankara: Gen Publisher.

\section{Copyrights}

Copyright for this article is retained by the author(s), with first publication rights granted to the journal.

This is an open-access article distributed under the terms and conditions of the Creative Commons Attribution license which permits unrestricted use, distribution, and reproduction in any medium, provided the original work is properly cited. 